\title{
O uso de sequências didáticas para o ensino de línguas cidadão.
}

\section{Jaqueline Barros}

Universidade de Brasília

\begin{abstract}
Resumo
Este trabalho vincula-se a área de Linguística Aplicada (Crítica) e concebe o termo letramento como grupo de práticas socioculturalmente situadas e ideologicamente construídas (STREET 1984). Sua realização teve como objetivo a busca pela promoção de um ensino de línguas estrangeiras cidadão (MOITA LOPES, 2003) por meio de Sequências Didáticas.

Palavras-chave: Sequências Didáticas; Ensino de Línguas; Letramento Crítico
\end{abstract}

\begin{abstract}
The scope of this paper falls within the area of Critical Applied Linguistics area, for it conceives the term "literacy" as a group of practices that are socioculturally situated and ideologically constructed (STREET 1984). Its main goal is to promote foreign language citizen teaching (MOITA LOPES 2003) through Didatic Sequence.

Key-works: Didatic Sequence; Language Teaching; Critical Literacy
\end{abstract}

\section{REFLEXÃO INICIAL}

$\mathrm{O}$ artigo aqui apresentado foi desenvolvido a partir da ideia de associar o cerne de uma pesquisa de Mestrado, pela qual se realizou a análise da representação de identidades sociais de classe, gênero e raça/etnia como maneiras de conceber o mundo no livro didático de língua estrangeira (espanhol) à utilização de Sequências Didáticas, doravante SD's com o emprego de gêneros textuais visando à promoção do letramento crítico na escola.

Constatou-se por aquela pesquisa a necessidade de o aprendiz de línguas estrangeiras identificar-se com a língua alvo. Essa identificação ou sensação de pertencimento pode vir a ser promovida pelo emprego de SD's, as quais devem ser desenvolvidas tendo como enfoque a produção, distribuição e circulação de gêneros discursivos "rentáveis" (COSTA, 2008, p.188). 
Os gêneros discursivos são considerados "rentáveis" quando permitem que o professor elabore atividades que promovam a (co)participação de seus alunos na construção de significados, levando em consideração a investigação de posicionamentos e ação no mundo originados pelos discursos (vozes) observadas nesses gêneros.

Para realizar a pesquisa, verificou-se que a escolha do livro didático pelo professor representa, muitas vezes, sua identidade pelas abordagens de ensino que o livro traz, layout, entre outras características.

Entretanto, deve ser parte do trabalho do professor analisar o que o livro não contém, ou seja, que lacunas ele deixa. Isso não significa que o professor deva abandonar o uso de livros didáticos, pois se trata de um instrumento que faz parte de sua formação profissional.

Para realizar a análise do livro didático, o professor deve levar em consideração o tempo de pesquisa, de preparação, e de editoração e os demais procedimentos até a chegada do livro ao mercado de consumo.

Tendo todas essas questões em mente, a pergunta que instigou a realização desse trabalho diz respeito à "Como a utilização de Sequências Didáticas por meio do emprego de gêneros discursivos promoverá o empoderamento dos aprendizes de língua(s) com o objetivo de que o ensino-aprendizagem seja realizado de forma cidadã?"

Como objetivo da pesquisa buscou-se promover o letramento crítico por meio da aplicação da uma SD elaborada a partir do levantamento da necessidade de adequação de uma atividade presente em uma unidade do livro didático, com o intuito de questionar alguns discursos hegemonicamente constituídos, constatados a partir da análise da representação de atores sociais via Linguística Sistêmico Funcional (Halliday, 2001) e Gramática do Design Visual (Kress e van Leeuwen, 1996), ambas vertentes da Análise Crítica do Discurso (Fairclough, 2005), abordagem teóricometodológica utilizada também para a realização desse trabalho.

Assim, esse artigo constitui-se de quatro seções. A primeira, estabelece a relação entre a abordagem teórico-metodológica Análise Crítica do Discurso e letramento crítico (segundo a teoria social do discurso); a segunda mostra a análise de uma atividade presente em uma unidade de um livro didático e a necessidade de complementá-lo problematizando questões por ele trazidas como discursos discriminatórios e homogeneizados e uma proposta para a utilização das SD's; a terceira mostra a relação entre os gêneros discursivos e ações de linguagem que podem ser 
promovidas por meio do uso de SD's. Na sequência, para finalizar o artigo, apresento algumas considerações sobre o que fora tratado.

Apesar de o objeto inicial da análise ter sido o livro didático de língua estrangeira, para esse trabalho a sequência didática assim constante no apêndice foi escrita em português com o objetivo de ampliar o acesso desse trabalho a professores de línguas em âmbito nacional.

\section{A ANÁLISE CRÍTICA DO DISCURSO E O LETRAMENTO CRÍTICO}

Todas as disciplinas do currículo escolar têm o compromisso e a responsabilidade de discutir questões que busquem a formação de um cidadão crítico. (Paulo Freire, 1996)

A citação de Paulo Freire nos remete aos estudos de Fairclough et al (1991), os quais concebem que o Letramento Crítico ${ }^{1}$ vincula-se a Conscientização Crítica da Linguagem (CCL) que liga-se, por sua vez, à Teoria Social do Discurso, teoria essa que constitui a Análise Crítica do Discurso (ADC).

O termo Conscientização Crítica da Linguagem tem sido usado desde a década de 80 para identificar uma abordagem de ensino de línguas que se fundamenta na atenção consciente às propriedades e ao uso da linguagem em vários contextos de ensino. Tal abordagem tem como objetivo trazer para a escola o entendimento de que as práticas sociais institucionalmente constituídas, pelas quais, algumas vezes, as relações desiguais de poder estão/ são veladas, podem ser modificadas, de forma que quanto maior o desenvolvimento da consciência crítica maior o desenvolvimento das capacidades de linguagem.

Assim, o discurso como prática social é permeado por uma relação dialética entre as estruturas e os eventos sociais, o que significa dizer que o discurso será restringido e moldado por estruturas que ao mesmo tempo o constituirão. Além disso, o discurso é também permeado pelo elemento chamado reflexividade, que conforme afirmam Chouliaraki \& Fairclough (1999), é alcançado pela luta social por meio das posições criadas dentro e fora das práticas sociais.

\footnotetext{
1 De acordo com Morgan (1997,p.2) trata-se do conjunto de práticas de linguagem pelas quais os aprendizes questionam quem constrói os textos [ou perspectivas/discursos/ideologias]; que representações são dominantes numa cultura determinada num determinado tempo; como os leitores passam a ser cúmplices das ideologias persuasivas dos textos; que interesses são privilegiados por tais representações e tais leituras; e, quando tais textos e leituras são injustos em seus efeitos, de que outra maneira eles poderiam ser construídos.
} 
As transformações sociais, econômicas, políticas e culturais atingem a esfera global na pós-modernidade, acarretando mudanças na própria identidade dos sujeitos sociais que têm os sentidos de lugar e do "eu" profundamente afetados, o que tem sido referenciado como uma perda de sentido. Para os autores, as formas sociais - produções sociais e totalmente passíveis de mudanças - estão sendo vistas como partes da natureza, ou seja, estão sendo naturalizadas. (CHOULIARAKI \& FAIRCLOUGH, 1999, p.26)

De acordo com Fairclough (1999), nas práticas sociais, por meio da linguagem, são manifestados discursos como parte irredutível das maneiras como agimos e interagimos, representamos e identificamos a nós mesmos, aos outros e a aspectos do mundo em contextos históricos, políticos e culturais, lançando mão de discursos, gêneros e estilos específicos.

A Análise Crítica do Discurso, permeada pela Consciência Linguística Crítica, tem como finalidade verificar os efeitos ideológicos que constituem o texto. Ela propõe ainda, o direcionamento dos sentidos que atuam a serviço de projetos particulares de dominação e exploração, contribuindo para a modificação ou sustentação de identidades, conhecimentos, crenças, atitudes e valores de forma assimétrica.

$\mathrm{O}$ arcabouço da análise denominado tridimensional permite análise de diversas áreas da vida social. Os variados aspectos desse arcabouço podem ser ou não inseridos em uma dada análise a depender do pesquisador os pontos necessários para sua proposta analítica.

O modelo tridimensional de Fairclough (2008) será apresentado a seguir de acordo com as dimensões textual, interpretativa e explanatória. Posteriormente serão mencionadas as categorias pertencentes a cada dimensão apenas para fins didáticos, pois essas dimensões se interrelacionam.

De acordo com Pedrosa et al (2010), baseados em Fairclough (2008), a descrição é realizada pela análise textual que consiste na análise das características formais do texto; a interpretação é realizada pela prática discursiva, com a investigação do uso das convenções e a explicação ou explanação é realizada pela análise social, situando o uso político e ideológico da interação e as relações de poder e valores discriminatórios.

Os estudos realizados por Pedrosa et al (2010) apontam que para a realização da análise textual são importantes categorias como vocabulário (lexicalização), gramática, coesão e estrutura textual.

No que concerne ao vocabulário (FAIRCLOUGH, 2008), estão inseridos nessa categoria os processos de lexicalização e de significação do mundo, considerando-se o momento histórico e os grupos sociais envolvidos. 
Dentro de lexicalização, pode-se falar em relexicalização, como a representação do domínio das experiências que contêm significado político e ideológico, uma vez que nos sentidos que as palavras possuem podem estar implícitas lutas de poder. Destarte, as metáforas também possuem implicações ideológicas de acordo com as seleções dos autores que as elencam ou criam.

Com relação à gramática, trata-se da representação de uma combinação de sentidos ideacionais, interpessoais e textuais, o que implica escolha de identidades sociais, de relações e de crenças. Para essa categoria, devem ser levadas em consideração também as dimensões transitividade, pela qual podem ser verificados tipos de processo (ação, evento), participantes favorecidos no texto, escolhas de voz (ativa ou passiva), nominalização dos processos e tema ${ }^{2}$. Há também neste item a padronização de entonação e a fala hesitante, o que acarreta o comprometimento do falante com as proposições que compõem a interação (quando nos referimos a textos orais transcritos).

Compõem a categoria de estrutura textual a polidez ${ }^{3}$ (representada pelas convenções sociais relativas às relações sociais entre os participantes das interações) e o ethos (manifestação pelo corpo inteiro e "não só pela voz") para análise do discurso oral, em entrevistas, por exemplo.

Concernente ainda à subcategoria ethos, pode-se analisar, por exemplo, textos imagéticos ${ }^{4}$ como gravuras e fotografias, levando em consideração a análise de categorias relacionadas às ordens do discurso como: a metafunção ideacional; a metafunção interpessoal; e a metafunção textual, conforme apresentado a seguir:

- metafunção ideacional - diz respeito à representação das experiências de mundo por meio da linguagem, envolvendo: estrutura narrativa (ação transacional, ação não transacional, reação transacional, reação não transacional, processo mental, processo verbal); estrutura conceitual (processos classificacional, analítico e simbólico). As ações correspondem ao sentido em que estão apresentadas, se estão diretamente

\footnotetext{
${ }^{2}$ De acordo com Fairclough (2008), trata-se de proeminência informacional e modalização, escolha de unidades gramaticais como verbos modais, tempos verbais, advérbios modais e seus adjetivos equivalentes.

3 Estratégias de polidez linguística visam o estreitamento da relação texto versus leitor, visando a evitação do confronto, objetivando o destaque dos pontos positivos e o reconhecimento do locutor/autor/escritor como alguém que partilha das mesmas preocupações que o receptor/leitor/aluno.

${ }^{4}$ Todas as categorias utilizadas para análise de imagens foram mencionadas pela gramática do design visual (GDV) de Kress e Van Leeuwen (2006), criada pelos autores com base na linguística sistêmico funcional (LSF) de Halliday, as quais serão detalhadas para análise das imagens elencadas neste trabalho.
} 
encaminhadas ao interactante ou interlocutor ou se o locutor porta algum objeto (o que pode-se dizer, compõe sua identidade no momento da fala)

- metafunção interpessoal - diz respeito à interação e envolve os significados sobre o nosso papel nos relacionamentos com outras pessoas e nossas atitudes em relação a elas. Fazem parte dessa análise: Participantes envolvidos na imagem: interactantes e representados; estratégias de aproximação/afastamento para com o leitor: Tipo de olhar (demanda ou oferta); perspectiva: objetividade ou subjetividade; distância social: formalidade ou informalidade.

- metafunção textual - refere-se aos significados sobre como aquilo que estamos dizendo se articula internamente, relaciona-se com o que foi dito antes e com o contexto à nossa volta. Modos de organização do texto: valor de informação (ideal-real, dadonovo); saliência (elementos mais salientes que definem o caminho de leitura); moldura (o modo como os elementos estão conectados na imagem)

De acordo com Pedrosa et al, (2010), a segunda dimensão (análise discursiva) relaciona-se à prática social (análise discursiva) como algo que as pessoas produzem e apreendem com embasamento em procedimentos compartilhados consensualmente.

Assim, a análise discursiva nos relata sobre um conjunto de regras anônimas, históricas, que são sempre determinadas no tempo e no espaço, as quais definiram, em um determinado período e para uma determinada área social, econômica, geográfica ou linguística, as condições de exercício da função comunicativa.

A primeira subdimensão da análise discursiva refere-se à produção do texto, a qual é constituída pela especificação dos tipos de discurso apresentados sob análise (interdiscursividade) ${ }^{5}$ e a especificação com que outros textos estão presentes no texto apresentado (intertextualidade), como fragmentos que podem estar explicitamente delimitados ou miscigenados na referida mensagem promovendo assimilação, contradição ou ressonância, e às vezes, ironia.

A segunda subdimensão da análise discursiva refere-se à distribuição do texto, representada pelas cadeias textuais que são as audiências antecipadas pelo produtor. As cadeias textuais podem ser complexas como: reportagens, análises e comentários, artigos acadêmicos; ou simples como uma conversa informal, por exemplo.

\footnotetext{
${ }^{5}$ De acordo com Bakhtin (1999), a interdiscursividade é a presença não de enxertos, mas de toda a configuração de outros discursos em um texto, em consonância com as convenções discursivas que norteiam sua produção.
} 
Com relação à terceira subdimensão da análise discursiva, tem-se o consumo do texto, referindo-se este à coerência, por considerar as implicações interpretativas das particularidades intertextuais e interdiscursivas do texto.

A próxima seção apresenta a análise de uma atividade de um livro didático de espanhol, realizada pela abordagem teórico-metodológica descrita.

\section{ANÁLISE DO LIVRO DIDÁTICO (VIA ADC) E A CONSTATAÇÃo DA NECESSIDADE DE COMPLEMENTÁ-LO}

De acordo com Gramsci (apud OLIVEIRA, 2013, p.32) a escola como organização educacional representa um mecanismo muito importante de difusão ideológica. Isso se evidencia pela autoridade de que o professor é investido perante a comunidade escolar quando, por exemplo, escolhe os temas a serem estudados pelos alunos, decidindo o que é certo e o que é errado.

Para Gramsci (idem), outra evidência de difusão ideológica pela qual a escola se ancora ocorre pela importância dada ao livro didático, razão pela qual seu conteúdo é rigidamente controlado pelo Ministério da Educação em nível nacional e pelas Secretarias de Educação nos níveis municipal e estadual. Isso torna as pesquisas embasadas em análises de materiais didáticos (livros) relevantes, conforme nos aponta Tilio:

uma análise do LD contribui para que o professor se abdique de seus próprios critérios de valor. Fazendo-o de forma crítica e autocrítica, levará em conta que esse instrumento, apesar de todo o esforço para mudança, nunca deixará de ser um meio e que, por isso mesmo, não poderá constituir-se de um fim em si mesmo. (TILIO, 2006, p.32)

Levando em consideração a ideologia que poderá ser vinculada pelos LD's concordamos com Ramos no sentido de que

\footnotetext{
para ter o seu uso otimizado, o livro didático precisa receber, no que concerne aos conteúdos, um tratamento mais contemporâneo por parte das pessoas que dele se utilizam. Este tratamento deve primar para que a interação social seja mola propulsora do processo de aprendizagem, e que ela situe o aprendiz no mundo em que vive e não deixe de sinalizar possíveis diferenças de contextos sociais e culturais existentes no país. (RAMOS, 2009, p. 195)
}

Nesse sentido, para van Dijk, (2008, p.34) a inclusão dos estudos críticos do discurso (ECD) no currículo escolar torna-se relevante, pois possibilita a formação de 
cidadãos mais conscientes e dispostos a desenvolver estratégias discursivas de dissensão e resistência.

Assim, por meio da Análise Crítica do Discurso, posicionamentos discursivos degradantes naturalizados podem ser questionados. Como exemplo, apresentamos a seguir a análise de uma atividade constante de um livro didático de língua estrangeira.

A figura 01, apresentada ao final da análise, está localizada na unidade (C), na página 42, do livro titulado Español en marcha - curso de español como lengua extranjera, com o texto intitulado: "A viajem dos pobres".

Ela aparece de forma descontextualizada, como exemplo do gênero discursivo artigo de jornal para os estudantes. Os autores do livro (supostos autores do texto) solicitam por meio de um exercício de escrita que os alunos desenvolvam um artigo sobre as vantagens e desvantagens de viver só e as vantagens e desvantagens de viver na companhia de alguém.

Ao contrário do que se poderia pensar, o enunciado da última questão solicita que os estudantes leiam o artigo e busquem seis erros de coerência textual, levando para bem longe a intenção de desenvolver uma argumentação sobre temas como racismo, discriminação e questões de poder, que poderia ser realizada por meio de um debate ou discussão mais aprofundada.

De acordo com o autor do texto, os "pobres" (famílias inteiras) atraídos pelas riquezas dos mencionados países realizam, sem malas, a "viagem da morte" até o "paraíso" em busca de trabalho, alimento, "liberdade" e um futuro melhor para seus filhos.

De acordo com a metafunção ideacional, a qual expressa um acontecimento do mundo material (KRESS e VAN LEEUWEN, 2001), a imagem que acompanha o texto traz uma representação narrativa, por mostrar uma ação pela qual homens e mulheres navegam em direção ao "paraíso". Trata-se de uma ação não transacional caracterizada pela presença de participantes representados que buscam interação, apelam para uma identificação com o leitor. Isso pode ser observado por meio da análise do direcionamento do olhar (vetor) expresso pelos atores representados na imagem.

A complementação da análise dessa imagem com respeito à metafunção interpessoal, que busca verificar o tipo de interação social existente entre o autor e o leitor por meio das dimensões do olhar, do enquadramento e da perspectiva, permitenos dizer que se trata de uma imagem de demanda pela qual o ator tenta criar um vínculo direto com o leitor, ainda que pelo tamanho da imagem e pelo ângulo do qual os 
atores sociais estão representados (enquadramento e perspectiva) tenhamos a nítida impressão de distanciamento entre os atores e o leitor. Esse distanciamento provocado pelo tamanho da imagem apresentada aos leitores pode significar que a história contada não parece real ou não faz parte de realidade conhecida pelo leitor. Pressupõe-se que o objetivo que os autores têm com essa estratégia é de que o leitor trabalhe com o texto considerando a fotografia como meramente ilustrativa.

Isso se confirma pela análise da imagem realizada a partir da metafunção textual, a qual nos diz sobre a coerência entre a mensagem e o contexto por ela apresentado (layouts). A observação relacionada às categorias concernentes a essa metafunção permite dizer que a imagem, por estar localizada horizontalmente à direita da página e verticalmente na parte superior, representa um dado novo e imaginado (ou em outros contextos algo idealizado). Destarte, os autores deixam a interpretação e a discussão sobre questões de grande importância para os jovens sobre racismo, migração e a perda de identidade dos povos noroeste da África "à deriva".

O texto utilizado como exemplo de artigo para a composição dos estudantes fala sobre a imigração ilegal de homens, mulheres e crianças que se aventuram em perigosas viagens, chegando a desafiar a morte para fugir da fome e da guerra. $\mathrm{O}$ autor do texto afirma que com certeza os imigrantes encontram em países como Espanha, Itália e Estados Unidos uma vida melhor, uma melhor organização social e que nos anos 60 e 70 a França representava para essas pessoas o paraíso. O autor também relata que o que no passado representava o paraíso pela promessa de emprego e alimento, hoje significa a perda da identidade nacional e cultural porque os filhos de imigrantes árabes que moram nesses países já não se consideram árabes e tampouco possuem identidade francesa.

No final do texto, no entanto, é mencionado que os países citados receberam no passado aqueles refugiados porque necessitavam de mão de obra para a indústria e para a agricultura, confirmando o processo histórico de colonização dos países africanos pelos países europeus. A preocupação do autor do livro está em mostrar a condição de inferioridade de uma raça em detrimento à outra. Por meio das estratégias de deslocamento e eufemização, o autor do texto dissimula a exploração sofrida pelos imigrantes classificando-os como pobres que "viajam para o paraíso para obter melhores condições de vida". Eles não possuem nada, pois "viajam sem malas", eles não tem nem mesmo nome. Essa pode ser confirmada pelo trecho; "Todos hemos oído 
hablar estos últimos anos de pateras ${ }^{6} y$ cayucos $y$ de inmigración clandestino en España, Italia, Europa del norte, Estados Unidos de América, pero no nos enteramos bien de los motivos que empujan a hombres y mujeres, incluso a niños, a efectuar lo que algunos periodistas llaman el viaje de la muerte"

Podemos dizer então que os imigrantes são os "estranhos" com relação ao perfeito mundo europeu, pois não se encaixam no mapa cognitivo, moral ou estético do mundo, poluindo a alegria com a angústia e tornando tênues as linhas de fronteira que devem ser claramente vistas (Bauman, 1999).

Para Ramalho (2006), por meio de classificações que legitimam a diferença é que a injustiça social é naturalizada. Essa injustiça iniciou-se pela atração que as metrópoles passaram a exercer sobre populações pobres originando o movimento de proliferação deste tipo de imigração. Dessa forma, ao mesmo tempo em que os processos de globalização unem no tempo espaços geograficamente afastados, separam mundos sociais que compartilham o mesmo espaço-tempo.

A análise da imagem, ou seja, a maneira como os autores utilizam a foto de africanos atravessando o continente em busca de melhores condições de vida e do texto que acompanha a imagem permitem dizer com relação às questões de ideologia (cf. Thompson, 2005) que várias são as estratégias de construção simbólica utilizadas para alienar os leitores ideologicamente.

Desse modo, por meio da racionalização o texto nos diz que milhares de africanos enfrentam perigos porque viajam clandestinamente. Pela universalização fazem-se referência às pessoas nascidas em países pobres que viajam para os países ricos; já pela narrativização, o autor menciona o fato de que todos têm ouvido falar nestes últimos anos sobre a imigração clandestina para a Espanha, Itália e Estados Unidos, ocultando o discurso como formas de legitimação do processo de dominação dos países "ricos" sobre os países "pobres".

As estratégias de legitimação misturam-se às estratégias de reificação por meio dos processos de naturalização. Nesse sentido, o texto apresenta de forma naturalizada pessoas de baixo ou nenhum poder aquisitivo em busca de uma vida melhor que se deslocam de um continente a outro arriscando suas vidas. Além dos processos descritos há a presença da estratégia de eternalização, pela qual poder-se-ia dizer que os países considerados pobres não se desenvolverão a ponto de tornar-se ricos, não havendo,

\footnotetext{
${ }^{6}$ Trata-se de um tipo de barco também usado para pesca, muito utilizado pelos imigrantes ilegais para atravessar o oceano atlântico de Marrocos até a Espanha.
} 
dessa forma, perspectiva de mudança para essas pessoas, a não ser que sobrevivam por meio do trabalho "escravo", nos países onde se refugiaram.

Ainda que não haja nenhuma referência de autoria, o texto tenta contar a história dos imigrantes africanos que viajam de barco à França. A mesma história é contada por Fanon (2008), a qual retrata a perda de identidade dos antilhanos que buscam melhores condições de vida no continente europeu. Quando estes retornam a sua terra natal veemse como diferenciados (há uma distinção) de seus costumes, sua vestimenta, seu sotaque. Trata-se de uma espécie de desenraizamento ocasionado pela "vontade de tornar-se branco". Nos termos de Silva (2004), trata-se da ideologia do branqueamento ${ }^{7}$.

Nas cidades de "acogida", termo que representa o local onde se refugiam essas pessoas, elas recebem um tratamento discriminatório, participam de trabalhos cuja remuneração é ínfima (trabalham como catadores de algodão ou em pequenas fábricas) ou são alistadas ao exército, como se pode observar no texto.

No que se refere à voz que deveria ser dada aos aprendizes, nota-se que o enunciado da questão em momento algum solicita do leitor a retomada do assunto mencionado pelo texto modelo. Os autores (discurso do texto e não da imagem) requerem do leitor que ele escreva um texto contando uma história que pode ser inclusive imaginária, como se a história que os autores tentaram contar (porque apresentam fragmentos do sofrimento dos africanos no século passado) fosse fruto da imaginação destes. Como se fora irreal.

Pelo fato de a história ter sido contatada por meio de uma perspectiva, há facilidade em solicitar aos alunos que façam o mesmo. Disso temos que as identidades de raça/etnia como apresentadas no texto e na imagem analisados são essencializadas e não há problematização do que fora relatado pelo suposto autor.

Assim, podemos aproveitar os discursos expostos nos textos do livro didático para analisar o dito, o declarado, e a força dele para a construção de identidades mais ou menos valorizadas nos cenários de ensino-aprendizagem de espanhol na contemporaneidade.

\section{A SEQUÊNCIA DIDÁTICA, OS GÊNEROS DISCURSIVOS E AS AÇÕES DE LINGUAGEM}

\footnotetext{
${ }^{7}$ De acordo com Silva (2004) trata-se de uma ideologia que busca justificar a opressão e a inferiorização por meio da destruição de uma identidade, da autoestima e do reconhecimento dos valores e potencialidades do oprimido com a finalidade de subordinação ou subestimação.
} 
No que concerne as Sequências Didáticas que complementam as atividades do livro didáticos, trouxemos os conceitos desenvolvidos por Dolz e Schneuwly (2001). Esses autores definem as Sequências Didáticas como uma sequência de módulos de ensino, organizados conjuntamente para melhorar determinada prática de linguagem. Instaura-se por meio de sequência didática uma relação de apropriação entre uma prática de linguagem e os instrumentos que facilitam essa apropriação. Tais instrumentos são gêneros discursivos. Eles são, de acordo com Bakhtin (1979), tipos relativamente estáveis de enunciados caracterizados por conteúdo temático, estilo e construção composicional. Esses enunciados são determinados por uma necessidade ou intenção do locutor para com um interlocutor.

A dita apropriação entre uma prática de linguagem e os gêneros discursivos promove capacidades de linguagem, isto é, faz-se necessário que o aprendiz se adapte às características do contexto e do referente de interação (capacidade de ação), mobilize modelos discursivos (capacidades discursivas); domine operações psicolinguísticas e as unidades linguísticas (capacidades linguístico-discursivas) para realizar uma produção textual.

Como estratégias de ensino para o uso de sequência didática podemos elencar a adaptação dos gêneros e de situações de comunicação às capacidades de linguagem apresentadas pelos alunos; aos objetivos visados; ao itinerário a ser percorrido para alcança-los; à colaboração com os outros alunos para facilitar as transformações propostas para a (re)construção do gênero discursivo e à avaliação dessas transformações.

Tomando como exemplo a pesquisa realizada por Rojo (2010), pela qual o texto é considerado material concreto sobre o qual se exerce um conjunto de ações de aprendizagem, sobretudo leitura e produção de textos, para a pesquisa aqui realizada, o gênero discursivo utilizado pertence ao domínio social de comunicação denominado relato, isto é, traz para os interlocutores uma representação identitária pelo discurso de experiências vividas, situadas no tempo, tratando-se, portanto, de uma notícia.

Assim, com a finalidade de problematizar as questões trazidas acerca do letramento crítico para o trabalho com o texto mencionado, foi apresentado aos alunos do $3^{\circ}$ ano "N" de um colégio de Ensino Médio, localizado no Distrito Federal, um artigo do jornal BBC publicado em 14 de setembro de 2015, cujo tema da manchete tratava da imigração ilegal na Europa. 
Após realizar a análise desse gênero discursivo com os alunos, levando em consideração os aspectos de tema, estilo e composição para analisar os esquemas de produção, recepção e circulação, solicitei aos alunos que realizassem ponderações sobre questões como: a existência de estrangeiros na cidade de Brasília; as formas de discriminação que essas pessoas sofreram ou ainda sofrem; e os motivos que levam as pessoas a migrarem de um país a outro.

Os relatos dos alunos, os quais serão levados para um blog, por uma questão de espaço, serão cenas a serem escritas em um outro artigo.

Abaixo apresenta a sequência didática utilizada. 


\section{Sequência Didática 01}

1) Agentes discursivos: Alunos do curso de Português/ Espanhol

2) Gênero: Artigo de Jornal - Notícia em formato de blog

3) Suporte: Livro didático

4) Sugestão de documento: Artigos de jornal e notícias do livro didático e de diversas outras fontes de informação.

5) Ações de linguagem: Compreensão leitora e Produção Escrita

6) Objetivos:

a. Apropriar-se do gênero artigo de jornal - notícia;

b. Utilizar elementos linguístico-discursivos referentes à linguagem da ação de noticiar algo;

c. Propiciar o reconhecimento e uso dos tempos pretérito e presente do indicativo em espanhol e em português

d. Promover o letramento crítico em sala de aula

7) Tempo estimado: Duas aulas de 50 minutos

8) Etapas da sequência:

a. Sem mostrar os documentos aos alunos, fazer um levantamento, se eles já leram e produziram um artigo de jornal (notícia);

b. Fazer a leitura e interpretação dos artigos retirados do livro, sempre deixando com que os alunos leiam e tentem interpretar;

c. Após a leitura e interpretação, refletir com os alunos as seguintes questões:

Qual é a finalidade de uma notícia ou artigo de jornal? (Aproveitar esse momento para levar os alunos a observarem a intenção, ideologia, do(s) autor(es) e mostrar nos textos onde essas intenções estão mais marcadas, em que palavras, seria bom destacá-las no quadro).

Que elementos não podem faltar em um artigo de jornal? (Deixar que os alunos expressem o que já sabem. O professor apenas acrescenta, aproveitando para indagá-los de forma a levá-los a pensar na construção do gênero).

d. Depois desses questionamentos, instruir os alunos a analisarem as palavras que foram colocadas no quadro para que eles possam refletir e chegar à conclusão de que este tipo de gênero pede a presença de verbos no pretérito perfeito e presente do indicativo.

e. Elaborar com os alunos possíveis trechos de notícias direcionados para o tema tratado na aula, para que eles possam observar melhor os tempos verbais trabalhados;

f. Propor a confecção de notícias em espanhol e português. (Orientar os alunos para que eles pensem em como vivem as pessoas em situação de imigração ilegal e por que o fazem).

9) Contexto de produção e uso: expressar-se em ações de linguagem escrita ao produzir uma notícia ou artigo de jornal.

10) Elementos linguísticos-discursivos; pretérito perfeito e presente do indicativo, uso da pontuação, uso da acentuação (pronomes), adjetivos;

11) Reflexão crítico- pedagógica: Os alunos conseguem pensar sobre a ideologia que permeia as notícias e os artigos de jornais. Conseguem propor um contra discurso ou dar voz aos excluídos, mesmo que apresentem alguma dificuldade quanto as ações de linguagem. Atividades complementares: Atividade de reescrita dos textos produzidos pelos alunos com o intuito de verificar possíveis inadequações gramaticais

\section{REFLEXÕES PARA FINALIZAR}

O ensino crítico relaciona-se com a forma como se ensina em sala de aula, seus objetivos, seu papel na sociedade e a habilidade de agir reflexivamente. (Aparecida de Jesus Ferreira, 2006, p.33) 
A partir dos anos 90 os PCNs têm feito forte apelo ao uso de gênero como objeto de ensino de línguas, com enfoque em leitura e produção textual. Indicando o lugar do texto (oral/escrito) - unidade de trabalho - e, logo, como suporte de aprendizagem e de propriedades da linguagem, uma vez que poderão suprir finalidades sociais do ensino e desenvolver as capacidades dos alunos em domínios diversos, a reflexão sobre a relação do homem com o mundo e consigo mesmo, isto é, a relação entre o discurso, prática social e a identidade.

No que concerne ao ensino de línguas e a outras disciplinas, de acordo com Freire (1987, 1996), Giroux (1980;1997), Hooks (1994) e outros, o ensino crítico objetiva fazer que os alunos reflitam sobre o seu papel na sociedade, visando direitos iguais e justiça social por meio da discussão sobre conceitos de ideologia, poder, classe social, consciência crítica e empoderamento relacionando-os a raça, gênero e classe.

\section{REFERÊNCIAS}

ACOSTA, M.P.T; RESENDE, V.M. "Não deu no rádio, no jornal ou na televisão" Análise discursiva crítica de textos do jornal O Trecheiro. In: Maria Aparecida Resende Ottoni; Maria Cecília de Lima (Orgs.). Discursos, identidades e letramentos: abordagens da Análise de Discurso Crítica. São Paulo: Cortez, 2014, p.142-172.

AMOSSY, Ruth. Les idées reçues. Paris: Nathan, 1991.

BAKHTIN, M. Os gêneros do discurso. In: Estética da criação verbal. São Paulo: Martins Fontes, 1979, p. 277-326.

BARROS, J.S. Identidades sociais de classe, gênero e raça/etnia representadas no livro didático de Espanhol como língua estrangeira. Dissertação (Mestrado em Linguística Aplicada) - Instituto de Letras, Universidade de Brasília, Brasília, 2013.

BAUMAN, Z. Tempo/ Espaço. Modernidade líquida. In: BAUMAN, Z. Plínio Dentzien (Trad.) Rio de Janeiro: Jorge Zahar Ed., 2001.

BAUMAN, Z. Globalização: as conseqüências humanas. Trad. Marcus Penchel. Rio de Janeiro:Zahar, 1999.

CALDAS-COULTHARD, C.R. Considerações sobre análise crítica do discurso, extensões pedagógicas e representação de gênero. In: MATEUS, E; OLIVEIRA, N.B. (Orgs.) Estudos Críticos da Linguagem e Formação de Professores/as de Línguas: contribuições teórico-metodológicas. Campinas, SP: Pontes Editores, 2014. p.99 -119.

CASTELLS, M. O poder da identidade. Trad. K.B.Gerhardt. São Paulo: Paz e Terra, 2001. 
CHOULIARAKI, L; FAIRCLOUGH, N. Discourse in late modernity: rethinking critical discourse analysis. Edinburgh: Edinburgh University Press, 1999.

COSTA, E.G.M. Gêneros discursivos e leitura em língua estrangeira. Revista do GEL, São Paulo, v.5, n.2, p.181-197, 2008.

CRISTOVÃO, V.L.L. Sequências Didáticas para o ensino de línguas. In: DIAS, R.; CRISTOVÃO, V. L. L. (Org.). O Livro Didático de Língua Estrangeira: múltiplas perspectivas. $1^{\text {a }}$ ed. Campinas: Mercado de Letras, 2009. p. 305-344.

FAIRCLOUGH, N. Critical discourse analysis: papers in the critical study of language. New York: Longman, 1995.

Discurso e mudança social. MAGALHÃES, I. (Trad.). Brasília:

Editora Universidade de Brasília, 2008.

FANON, F. Pele negra, máscaras brancas. Frantz Fanon; tradução de Renato da Silveira - Salvador: EDUFBA, 2008, p.194.

FERREIRA, A.J. Formação de professores raça/etnia: reflexões e sugestões de materiais de ensino em português e inglês. $2^{\mathrm{a}}$.ed., ver. Cascavel: Assoeste, c2006.

FOUCAULT, M. História da sexualidade - Vol.1: A vontade de saber. 11 ed. Rio de Janeiro: Graal, 1988.

FREIRE, P. Pedagogia da autonomia: saberes necessários à prática educativa. São Paulo: Paz e Terra, 1996.

. Pedagogia do oprimido. Rio de Janeiro: Paz e Terra, 1987.

GIROUX, H. Pedagogy and the politics of hope: theory, culture and schooling, a critical reader. Boulder: Westview, 1997.

. Critical Theory and Rationality in Citizenship Education. Curriculum Inquiry, v.10, n.4, p.329-366, 1980.

HALLIDAY, M.A.K. Introduction to functional grammar. London: Edward Arnold, 1985.

HOOKS, B. Teaching to transgress education as the practice of freedom. London: Routledge, 1994.

KRESS, G; VAN LEEUWEN, T. Multimodal Discourse. London: Edward Arnold., 2001.

London/New York: Routledge, 1996.

Reading imagens: the grammar of visual design. 
LIMA, C.H.P; P, S.M.O; A, A. M. T. (Org.). Incursões Semióticas: Teoria e Prática de Gramática, Sistêmico-Funcional, Multimodalidade, Semiótica Social e Análise Crítica do Discurso. Rio de Janeiro: Livre Expressão, 2009.

MEURER, J.L; BONINI, A; MOTTA-ROTH, D. Gêneros: teorias, métodos, debates. In: MEURER, J.L; BONINI, A; MOTTA-ROTH, D. (Orgs.). São Paulo: Parábola Editorial, 2005.

MORGAN, W. Critical literacy in the classroom: the art of the possible. New York: Routledge, 1997.

NOVODVORSKI, A. A recontextualização do ensino de Espanhol no Brasil na linguagem jornalistica: uma análise crítico-discursiva da representação de atores sociais. In: Maria Aparecida Resende Ottoni; Maria Cecília de Lima (Orgs). Discursos, identidades e letramentos: abordagens da Análise de Discurso Crítica. São Paulo: Cortez, 2014, p.111-141.

PEDROSA, C; OLIVEIRA, D \& DAMACENO, T. Caminhos teóricos e práticos em análise do discurso. Cadernos do CNLF, Vol.XIV, N.2, T.1. 2010. disponível em: http://www.filologia.org.br/xiv_cnlf/tomo_1/646-691.pdf.

RAMALHO, V \& RESENDE, V.M. Análise de discurso (para a) crítica: o texto como material de pesquisa. Campinas, SP: Pontes Editores, 2011.

RAMOS, R.C.G. O livro didático de língua inglesa para o ensino fundamental e médio: papéis, avaliação e potencialidades. In: DIAS, R; CRISTOVÃO, V.L. (Orgs.). O livro didático de língua estrangeira - múltiplas perspectivas. Campinas, SP: Mercado de Letras, 2009.p.173-198.

RESENDE, V.M.; RAMALHO, V. Análise do Discurso Crítica. São Paulo: Contexto, 2006.

ROJO, R. Letramentos Múltiplos, escola e inclusão social. São Paulo: Parábola Editorial, 2009.

Falando ao pé da letra: a constituição da narrativa e do letramento. Roxane Rojo. São Paulo: Parábola Editorial, 2010, 248 p.

SCHNEUWLY, B. Gêneros e tipos de discurso: considerações psicológicas e ontogenéticas. In: DOLZ, J. et al. Gêneros orais e escritos na escola. São Paulo: Mercado de Letras, 2011, $3^{\mathrm{a}}$ edição.

SILVA, A.C. A discriminação do negro no livro didático. 2.ed. Salvador: EDUFBA, 2004.

SILVA, D.E.G; LOPES, V.F. Diálogos teórico-metodológicos e práticas sociais de letramento:uma perspectiva crítica. In: MATEUS, E; OLIVEIRA, N.B. (Orgs.). Estudos Críticos da Linguagem e Formação de Professores/as de Línguas: Contribuições Teórico-Metodológicas. Campinas, SP: Pontes Editores, 2014. p.167192. 
SILVA, L. M. P. Enseñanza de español para brasileños: elaboración de material didáctico. In. SEDYCIAS, João (Org.). O ensino do espanhol no Brasil: passado, presente, futuro. São Paulo: Parábola, 2005. cap. 11. p. 182-194.

STREET, B. Literacy in Theory and Practice. Cambridge: Cambridge University Press, 1984.

TÍLIO, R.C. O livro didático de inglês em uma abordagem sócio-discursiva: culturas, identidades e pós-modernidade. Tese de Doutorado, Rio de Janeiro: Pontifícia Universidade Católica, 2006. Disponível em: http://www.maxwell.lambda.ele.pucrio.br/Busca etds.php?strSecao=resultado\&nrSeq= 8835@1

THOMSON, J.B. Ideologia e cultura moderna: teoria social crítica na era dos meios de comunicação de massa. Petrópolis, RJ: Vozes, 1995.

VAN DIJK.T. Critical Discourse Studies: A sociocognitive approach. In: WODAK, RUTH, MEYER, MICHAEL (orgs.). Methods of Critical Discourse Analysis. London: SAGE, 2009, p.62-86.

VAN LEEUWEN, T. A representation of social actors. In: PEDRO, Emília Ribeiro (Org.). Análise Crítica do Discurso: uma perspectiva sociopolítica e funcional. Lisboa: Caminho, 1997, p.169-222.

VIÚDEZ, F.C; DÍEZ, I.R; FRANCO, C.S. Español em marcha - curso de español como lengua extranjera, libro del alumno, V.4, 2007, p.42.

\section{A AUTORA}

Jaqueline Barros é mestre em Linguística Aplicada pela Universidade de Brasília. Sua área de interesse engloba letramento crítico, (multi)letramentos, material didático, ensino de espanhol, ensino inglês, ensino de português e Linguística Aplicada. Atua como professora substituta de espanhol da Secretaria de Educação do Distrito Federal e como tutora do curso de Letras da Universidade Aberta do Brasil (UAB-UnB).

E-mail: 28.jaqueline@gmail.com 
ANEXO I

Figura 1 - Unidade 4: Socialización - Seção D: Escribe, p.42

D. Escribe

\section{UN ARTI CULO PARA UNA REVISTA}

1. ¿Te gusta escribir para la revista de tu escuela? ¿Has escrito artículos en tu idioma? ¿Te resulta fácil o dificil? ¿Qué procedimiento sigues? Coméntalo con los compañeros.

Un buen artículo debe reunir algunas condiciones

- Tener un dirulo.

- Tener en cacna el publico al gue va dirigido. En función de los lectores, el estilo de un articulo puede sez más o menes formal.

- Tener una buena organización de las ideas. La estruc. tura mis usual comprende:

- Una incroducción. Puede ser una afirmación general o una pregunta.

- Uno o dos pirrafos con las ideas principales. Cada idea debe ser concretada con ejemplos.

- Un párrafo final de conclusión donde se resuma la idea principal y se dé la opinión personal.

- En cuanto al procedimiento, antes de empecar a re dactar es imprescindible recoger una lisa de ideas sobre el tema que se va a tratar. Una forma útil de reco. ger ideas es discutir en pequetios grupes y anotar lo que se le vaya ocurriendo a cada uno. Luego, hay que seleccionar aquellas ideas que parezcan mis interesantes para desarrollar el articulo.

2. Discute con tus compañeros y toma nota.

¿Es mejor wivir solo o acompatiado?

Ventajas y descentajas de cada situación.

3. Escribe un articulo de unas 150 palabras para la revista de la escuela donde estudias, sobre la pregunta anterior.

4. A continuación hay un articulo escrito por un estudiante para la revista de su escuela sobre el tema de la emigración. Léelo y encuentra los seis errores que contiene. Luego, comprueba con tu compafiero.

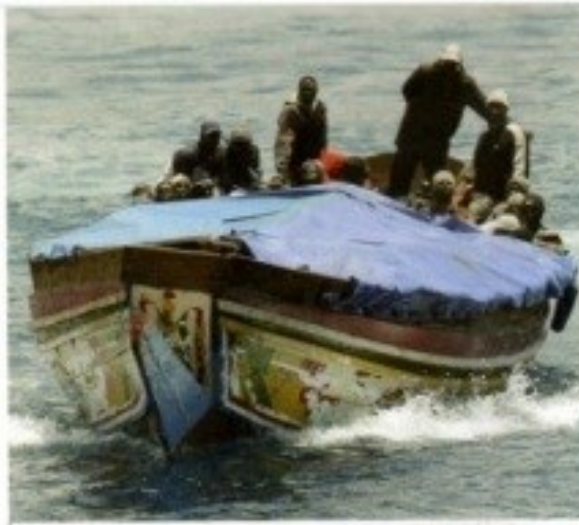

\section{El viaje de los pobres}

Quisiera bablar del viaje que effothiarni sin maletas miles de personas procedentes de paises pobres hacia paises ricos.

Todos hemos ofdo hablar estos últimos antos de pateras y cayucos $y$ de inmigración clandestino en Espafla. Italia, Europa del norte. Estados Unidos de América, pero no nos enteramos bien de los motivos que empujan a hombres y mujeres. incluso a niños, a efectuar lo que algunos periodistas llaman el "viaje de la muerte".

Los inmigrantes legales son conscientes de las dificultades que este viaje entraña. Desafian a la muerte porque la posibilidad de encontrar un futuro mejor les anima. En efecto, algunes huyen en paises que padecen hambre. Orros abandonan su país a causa de las dictaduras y las guerras.

Por supuesto, los inmigrantes encuentran en los paises de acogida una vida mejor, una organizacion social $y$ un futuro para sus hijos. Los magrebies los cuales emigraron en los ańos sesenta y setenta a Francia encontraron a este pais el paraiso que buscaban. Sin embargo, se dan cuenta hoy de que sus hijos han perdido so identidad árabe y no han adquirido a cambio una identidad francesa.

Hay que añadir que la llegada de los inmigrantes a los paises occidentales es debida al enriguecimiento de estos $y$ su aecesidad de mano de obra para la industria $y$ la agricultura.

Figura 1 - VIÚDEZ, F.C; DÍEZ, I.R; FRANCO, C.S. Español em marcha - curso de español como lengua extranjera, libro del alumno, V.4, 2007, p.42 